\title{
Are Lobe-Specific Mediastinal Lymph Node Dissections Reasonable for Peripheral Stage Ia Non-small Cell Lung Cancer?
}

\author{
Justin M. Karush ${ }^{1}$ \\ Department of Cardiothoracic Surgery, Rush University Medical Center, Chicago, IL
}

Lung cancer represents the leading cause of cancer death, with annual death rates higher than the next four cancers combined (breast, prostate, colorectal, and pancreas). ${ }^{1}$ However, while non-small cell lung cancer (NSCLC) may be curable by surgical resection, even tumors that appear to be localized may have lymph node metastases. As such, assessment of lymph nodes is important for accurate staging and to identify patients who may benefit from adjuvant systemic therapy.

In the era of lung cancer screening, we are seeing increased numbers of patients with clinical stage Ia disease. These small tumors create controversy on several fronts, including optimal extent of resection, need for surgical staging of the mediastinum, and extent of nodal dissection. It is generally accepted as standard of care that small (T1), peripheral primary lung cancers (NSCLC), with no clinical evidence of either N1 or N2 disease, can proceed to surgical resection without invasive staging of the mediastinum. This is based on a low rate of occult $\mathrm{N} 2$ disease in this cohort (3-6\%). ${ }^{2-4}$ However, at the time of surgery, it is incumbent upon the surgeon to rule out locally advanced disease. This rationale has led to favoring segmentectomy over wedge resections to ensure identification of occult N1 disease. Regarding evaluation of occult N2 disease, it is well-established that mediastinal lymph node dissection/ sampling adds no morbidity and minimal time to the operation. ${ }^{5}$ In order to omit a thorough assessment of the

\footnotetext{
(C) Society of Surgical Oncology 2019
}

First Received: 23 October 2019; Published Online: 6 November 2019

J. M. Karush

e-mail: justin_m_karush@rush.edu mediastinum for even peripheral clinical stage Ia tumors would require a high level of evidence that there was no chance of missing occult disease.

In the current issue of Annals of Surgical Oncology, Deng et al. ${ }^{6}$ retrospectively analyzed 590 patients with $\mathrm{cT}_{\mathrm{a}-\mathrm{c}} \mathrm{NOM} 0$ peripheral NSCLC who underwent segmentectomy or lobectomy. They analyzed patterns of occult mediastinal lymph node metastasis. The study is predicated on the possibility that lobe-specific lymph node dissection (L-SLND) might yield less morbidity than systematic lymph node dissection (SLND), which may be unnecessary given the low rate of metastasis from peripheral stage Ia lesions. The authors categorized mediastinal lymph node zones into upper (stations $2 \mathrm{R}, 3,4 \mathrm{R}$ on the right; stations $4 \mathrm{~L}, 5,6$ on the left), subcarinal (station 7), and lower (stations 8 and 9). They identified a 9.5\% overall rate of occult N2 disease.

Regarding the pattern of metastasis, the authors found that upper lobe tumors rarely metastasized outside of the upper LN zone (one station 7 and one station 9 metastasis for all upper lobe tumors bilaterally combined), and both of these were from tumors $>2 \mathrm{~cm}$. Lower lobe tumors had a more equal distribution of metastasis to all three $\mathrm{LN}$ zones, however only tumors $>2 \mathrm{~cm}$ (T1c) metastasized to an upper LN zone. The authors concluded that L-SLND for upper lobe cT1a-b tumors includes only upper zone lymph node stations, while lower lobe cT1a-b tumors require only lower and subcarinal $\mathrm{LN}$ zones.

Several points merit discussion to understand the current paradigm of managing peripheral cT1N0 NSCLC. First, it is well-established that the yield of occult N2 disease, especially that which is accessible by mediastinoscopy, is extremely low (3-6\%), and thus is typically and reasonably omitted. For the same reason, we generally omit positron emission tomography scans for cT1 peripheral tumors without computed tomography-positive mediastinal lymph 
nodes. As mentioned previously, the question as to whether a lymph node dissection increases operative morbidity was evaluated in a randomized controlled trial and none was found. ${ }^{5}$

It is also worth noting that the author's $9.5 \%$ rate of occult N2 disease is higher than previous reports. ${ }^{6}$ In a series from the Mayo Clinic that analyzed 945 patients with cT1N0 NSCLC, only a $3.7 \%$ rate of occult N2 disease was identified at the time of surgery. ${ }^{2}$ Additionally, this study included both peripheral and central tumors, the latter of which is more prone to metastasis to the mediastinum.

The current study is an excellent step forward to understanding the rates and pattern of metastasis of earlystage peripheral tumors, an entity we are fortunate to manage with increasing frequency owing in part to increased rates of lung cancer screening. They also identify what we know to be true about tumor biology, i.e. that tumor size is correlated with the propensity/ability to metastasize. As such, it appears that even within clinical T1 NSCLC, there are differences between T1a, T1b, and T1c tumors in terms of patterns and rates of metastasis. Future randomized controlled trials are needed to better understand this phenomenon and help guide our work-up and intraoperative management of these patients.

DISCLOSURES Justin M. Karush declares no conflicts of interest.

\section{REFERENCES}

1. Altekruse SF, Kosary CL, Krapcho M, et al. SEER Cancer Statistics Review, 1975-2007. Bethesda: National Cancer Institute; 2010. http://seer.cancer.gov/csr/1975_2007/, based on November 2009 SEER data submission, posted to the SEER website.

2. Defranchi SA, Cassivi SD, Wigle DA, et al. N2 disease in T1 nonsmall cell lung cancer. Ann Thorac Surg. 2009; 88(3):924-28.

3. Darling GE, Allen MS, Putman JB, et al. Randomized trial of mediastinal lymph node sampling versus complete lymphadenectomy during pulmonary resection in the patient with N0 or N1 (less than Hilar) non-small cell carcinoma: results of the ACOSOG Z0030 trial. J Thorac Cardiovasc Surg. 2011; 141(3):662-70.

4. Meyers BF, Haddad F, Siegel BA, et al. Cost-effectiveness of routine mediastinoscopy in computed tomography- and positron emission tomography-screened patients with stage I lung cancer. $J$ Thorac Cardiovasc Surg. 2006;131:822-9.

5. Allen MS, Darling GE, Pechet TT, et al. Morbidity and mortality of major pulmonary resections in patients with early-stage lung cancer: initial results of the randomized, prospective ACOSOG Z0030 trial. Ann Thorac Surg. 2006;81:1013-19.

6. Deng HY, Zhou K, Wang RL, et al. Lobe-specific lymph node dissection for clinical early-stage (cIA) peripheral non-small cell lung cancer patients: what and how? Ann Surg Oncol. 2019. h ttps://doi.org/10.1245/s10434-019-07926-3.

Publisher's Note Springer Nature remains neutral with regard to jurisdictional claims in published maps and institutional affiliations. 